\title{
Evaluation of antimicrobial susceptibility testing of Nocardia spp. isolates by broth microdilution with resazurin and spectrophotometry
}

\author{
Vivian Caso Coelho 1,2, Samara D’Ajuda Pereira Neves ${ }^{3}$, Mauro Cintra Giudice ${ }^{4,5,6}$, Gil Benard ${ }^{4,5}$,
} Marta Heloisa Lopes ${ }^{1,2}$ and Paula Keiko Sato ${ }^{*^{*}}$ (1)

\begin{abstract}
Background: Nocardia species are ubiquitous in natural environments and can cause nocardiosis. In the present study, the use of Resazurin salt and Spectrophotometry were proposed as alternative methods to reduce subjectivity in the interpretation of susceptibility results to antimicrobials by the broth microdilution method for Nocardia spp.

Results: The susceptibility of Nocardia spp. isolates to Amikacin, Ciprofloxacin, Minocycline and Trimethoprim-Sulfamethoxazole was evaluated by Minimum Inhibitory Concentration (MIC) determinations by the broth microdilution method. To verify cellular growth, the colour-changing dye Resazurin was applied, the Optical Densities were measured on a spectrophotometer, and both were compared to Clinical and Laboratory Standards Institute (CLSI) Gold Standard method (visual MIC determination). Percentages of essential and categorical agreements and interpretative categorical errors were calculated within each method (intra-reading) and between them (inter-reading). The Gold Standard visual reading demonstrated $100 \%$ of essential and categorical intra-reading agreements for Amikacin, and there was no error when compared with the alternative methods. For Ciprofloxacin, the comparison between the Gold Standard and the Spectrophotometric reading showed $91.5 \%$ of essential agreement. In the categorical intrareading analysis for Minocycline, there were 88.1 and $91.7 \%$ in the Gold Standard and in the Spectrophotometric readings, respectively, and $86.4 \%$ of concordance between them. High rates of categorical agreement were also observed on the Trimethoprim-Sulfamethoxazole analyses, with $93.7 \%$ for the Gold Standard, $84.9 \%$ for the Resazurin readings, and $80.5 \%$ between them.
\end{abstract}

Conclusions: The alternative methods with Resazurin and Spectrophotometric readings showed high agreement rates with the Gold Standard.

Keywords: Nocardia, Antimicrobial susceptibility testing, Broth microdilution, Resazurin, Spectrophotometry, Minimum inhibitory concentration

*Correspondence: paula.s@hc.fm.usp.br

${ }^{1}$ Laboratory of Medical Investigation in Immunology (LIM48), Hospital das Clinicas HCFMUSP, Faculdade de Medicina, Universidade de Sao

Paulo, Av. Dr. Eneas Carvalho de Aguiar 470, IMT 2, terreo, Sao Paulo, SP 05403-000, Brazil

Full list of author information is available at the end of the article

\section{Background}

The genus Nocardia sp. is a large group of gram-positive bacteria, aerobically living in soil, organic matter, and fresh or salt water. Nocardia belong to the family Nocardiaceae, from the suborder of aerobic actinomycetes that 
also includes Mycobacterium, Corynebacterium, Gordona and Tsukamurella $[1,2]$.

Several species of Nocardia can cause disease in humans, with a wide spectrum of clinical manifestations. In immunocompetent individuals, nocardiosis commonly occurs after traumatic inoculation of the microorganism, while the respiratory tract is often the initial site of infection in the immunocompromised [3]. Despite being potentially fatal as an opportunistic disease, the prevalence of nocardiosis is unknown in most countries, as it is not compulsorily notified. Additionally, the identification of Nocardia is challenging. These bacteria grow in specific media for mycobacteria and form partially acid-fast beaded branching filaments, similarly to mycobacteria, which frequently results in Nocardia being mistaken for Mycobacterium [4].

The identification of the species is necessary for an adequate treatment, but its effectiveness may depend on the antimicrobial susceptibility profile, widely diverse among Nocardia spp. Since nocardiosis can be fatal in the absence of treatment and there were reports of Nocardia resistance to sulfonamides, the susceptibility testing becomes even more important. In addition, there are new antibiotic agents that could be even more effective than the usual sulfonamide treatment $[5,6]$.

The Clinical and Laboratory Standards Institute (CLSI) currently recommends the Broth Microdilution (BMD) method to determine the Minimum Inhibitory Concentrations (MIC) of antimicrobial agents to establish the susceptibility of Nocardia spp. isolates [7]. However, Brown-Elliott et al. [8] already addressed the subjectivity in the visualization and interpretation of BMD method results. As an effort to reduce this bias, some reports applied the Resazurin, a blue reagent that changes to pink when reduced to resorufin because of the growth of cultured cells, such as bacteria and fungi [9-11]. Likewise, spectrophotometric readings of Optical Densities (OD) were also used to diminish subjective interpretation of BMD method results [12-14].

In the present study, the application of Resazurin and OD readings were investigated as alternative methods that could reduce subjectivity in the interpretation of susceptibility to antimicrobials testing on Nocardia spp. by broth microdilution assay.

\section{Results}

The Nocardia spp. isolates were evaluated in this study by the BMD method, and the use of Resazurin salt (visually determined MIC with Resazurin) and the OD reading (spectrophotometric determined MIC by ODs) were evaluated as alternative methods of result reading in comparison with the Gold Standard visual reading (CLSI recommended method with visually determined MIC).
The susceptibility profile of the evaluated Nocardia isolates, with respective modal MIC and ranges for Amikacin (AMK), Ciprofloxacin (CIP), Minocycline (MIN), and Trimethoprim-Sulfamethoxazole (TMPSMX) by BMD method are presented on Table 1 . Fifteen isolates were analyzed and most were susceptible to the evaluated antimicrobial drugs; four and ten isolates were resistant to MIN and to CIP, respectively.

The percentages of Essential (MIC values) and Categorical (susceptibility classification) Agreements were calculated for intra- (same reading method, independent assays) and inter-reading (different reading methods, same assay) comparisons, considering \pm 1 two-fold dilution for concordant results. The Pearson Correlation Coefficients (Pearson's r) and respective 95\% Confidence Intervals ( $95 \% \mathrm{CI}$ ) were determined on the inter-reading methods comparisons of MIC values. The Pearson's r-values range from -1 to +1 : values from 0 to +1 indicate a positive correlation, from 0 to -1 indicate a negative correlation, and 0.0 indicates no correlation at all. $P$-values of $<0.05$ indicate a significant correlation (Table 2).

The percentages of Essential Agreement (EA) for the three drugs on both intra- and inter-reading comparisons were higher than $80.0 \%$, and there were positive and significant correlations between the Gold Standard and both alternative methods, Resazurin and OD readings ( $P<0.0001$ for all comparisons). The EA percentages for CIP assays between the Gold Standard and the Resazurin readings, and between the Gold Standard and the OD readings were 90.7 and $89.4 \%$, respectively. For the AMK assays, all three reading methods showed $100 \%$ of Categorical Agreement (CA) in both intra- and inter-reading comparisons (Table 2).

For the CA, discrepancies of classification were calculated as percentages of errors defined as: Minor error, an intermediate result in the alternative assay and a resistant or susceptible result in the Gold Standard method, or vice-versa; Major error, a susceptible result in the Gold Standard method, but resistant in the alternative assay (false resistance); and Very Major error, a resistant result in the Gold Standard method, but susceptible in the alternative assay (false susceptible). Acceptable error levels were $\leq 10 \%$ for Minor, $\leq 3.0 \%$ for Major, and $\leq 1.5 \%$ for Very Major errors [14].

There were no categorical errors on the results of AMK. For CIP, on the other hand, $0.85 \%$ of Very Major errors were observed between the Gold Standard and the Resazurin readings, and $1.52 \%$ of Major errors between the Gold Standard and the OD readings. For the MIN assays, there were no Very Major and Major errors in the inter-reading comparisons, and the percentage of Minor errors ranged from 12.3 to $14.4 \%$ (Table 2). 
Table.1 Reading methods results of MIC and susceptibility from broth microdilution assays for Nocardia spp. isolates

\begin{tabular}{|c|c|c|c|c|c|c|c|}
\hline \multirow[t]{3}{*}{ Isolates } & \multirow[t]{3}{*}{ Drugs } & \multicolumn{4}{|l|}{ Visual Readings } & \multirow{2}{*}{\multicolumn{2}{|c|}{ OD Readings }} \\
\hline & & \multicolumn{2}{|l|}{ Gold Standard } & \multicolumn{2}{|l|}{ With Resazurin } & & \\
\hline & & Modal MIC (range) & asusc. (\%) & Modal MIC (range) & 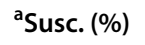 & Modal MIC (range) & ${ }^{\mathrm{a} S u s c .}$ (\%) \\
\hline \multirow[t]{4}{*}{ N. brasiliensis-83 } & AMK & $0.5(0.5-2.0)$ & 100.0 & $0.5(0.5-1.0)$ & 100.0 & $1.0(0.5-1.0)$ & 100.0 \\
\hline & CIP & $0.12(0.12)$ & 100.0 & $0.12(0.12)$ & 100.0 & $0.12(0.12)$ & 100.0 \\
\hline & MIN & $8.0(4.0-16.0)$ & 0.0 & $4.0(4.0-8.0)$ & 0.0 & $4.0(2.0-8.0)$ & 0.0 \\
\hline & TMP-SMX & $0.5(0.12-2.0)$ & 100.0 & $4.0(0.25-8.0)$ & 37.5 & $0.25(0.12-0.5)$ & 100.0 \\
\hline \multirow[t]{4}{*}{ N. brasiliensis-95 } & AMK & $0.5(0.5-1.0)$ & 100.0 & $2.0(0.5-2.0)$ & 100.0 & $1.0(0.5-1.0)$ & 100.0 \\
\hline & CIP & $4.0(4.0)$ & 0.0 & $4.0(4.0)$ & 0.0 & $4.0(2.0-4.0)$ & 0.0 \\
\hline & MIN & $1.0(0.25-1.0)$ & 100.0 & $0.5(0.25-2)$ & 90.0 & $1.0(0.5-1.0)$ & 100.0 \\
\hline & TMP-SMX & $0.12(<0.12-0.5)$ & 100.0 & $0.12(0.12-2)$ & 100.0 & $0.12(<0.12-2.0)$ & 100.0 \\
\hline \multirow[t]{4}{*}{ N. brasiliensis-129 } & AMK & $1.0(0.5-1.0)$ & 100.0 & $2.0(2.0-4.0)$ & 100.0 & $1.0(1.0-2.0)$ & 100.0 \\
\hline & CIP & $4.0(4.0)$ & 0.0 & $4.0(4.0)$ & 0.0 & $4.0(2.0-4.0)$ & 0.0 \\
\hline & MIN & $0.5(0.25-1.0)$ & 100.0 & $1.0(0.25-1.0)$ & 100.0 & $0.5(0.25-1.0)$ & 100.0 \\
\hline & TMP-SMX & $0.25(0.12-0.5)$ & 100.0 & $0.25(0.25-1.0)$ & 100.0 & $0.25(0.25-1.0)$ & 100.0 \\
\hline \multirow[t]{4}{*}{ N. brasiliensis-514 } & AMK & $0.5(0.5-1.0)$ & 100.0 & $0.5(0.5-1.0)$ & 100.0 & $0.5(0.5-4.0)$ & 100.0 \\
\hline & CIP & $0.12(0.12)$ & 100.0 & $0.12(0.12)$ & 100.0 & $0.12(0.12)$ & 100.0 \\
\hline & MIN & $4.0(4.0-16.0)$ & 0.0 & $8.0(4.0-8.0)$ & 0.0 & $4.0(2.0-8.0)$ & 0.0 \\
\hline & TMP-SMX & $2.0(0.25-8.0)$ & 62.5 & $4.0(2.0-32.0)$ & 14.3 & $0.12(0.12-8.0)$ & 87.5 \\
\hline \multirow[t]{4}{*}{ N. brasiliensis-519 } & AMK & $0.5(0.5)$ & 100.0 & $0.5(0.5-1.0)$ & 100.0 & $1.0(0.5-1.0)$ & 100.0 \\
\hline & CIP & $2.0(1.0-2.0)$ & 50.0 & $1.0(1.0-2.0)$ & 71.4 & $2.0(2.0)$ & 0.0 \\
\hline & MIN & $0.5(0.06-1.0)$ & 100.0 & $1.0(0.12-2.0)$ & 80.0 & $0.25(0.06-0.25)$ & 100.0 \\
\hline & TMP-SMX & $0.12(0.12-0.25)$ & 100.0 & $0.12(0.12-1.0)$ & 100.0 & $0.12(0.12-0.25)$ & 100.0 \\
\hline \multirow[t]{4}{*}{ N. brasiliensis-608 } & AMK & $2.0(0.5-2.0)$ & 100.0 & $2.0(0.5-2.0)$ & 100.0 & $2.0(2.0)$ & 100.0 \\
\hline & CIP & $4.0(0.12-32.0)$ & 22.2 & $4.0(2.0-4.0)$ & 0.0 & $4.0(0.12-4.0)$ & 33.3 \\
\hline & MIN & $0.06(0.06-0.12)$ & 100.0 & $0.06(0.06-0.5)$ & 100.0 & $0.06(0.06-0.12)$ & 100.0 \\
\hline & TMP-SMX & $1.0(0.25-1.0)$ & 100.0 & $0.5(0.12-1.0)$ & 100.0 & $0.25(0.12-025)$ & 100.0 \\
\hline \multirow[t]{4}{*}{ N. brasiliensis-775 } & AMK & $0.5(0.5-1.0)$ & 100.0 & $0.5(0.5-1.0)$ & 100.0 & $1.0(0.5-1.0)$ & 100.0 \\
\hline & CIP & $4.0(4.0)$ & 0.0 & $4.0(4.0)$ & 0.0 & $4.0(4.0)$ & 0.0 \\
\hline & MIN & $0.06(0.06-0.5)$ & 100.0 & $1.0(0.06-1.0)$ & 100.0 & $0.06(0.06-0.25)$ & 100.0 \\
\hline & TMP-SMX & $1.0(0.12-1.0)$ & 100.0 & $1.0(0.25-4.0)$ & 66.7 & $0.25(0.25-1.0)$ & 100.0 \\
\hline \multirow[t]{4}{*}{ N. brasiliensis-865 } & AMK & $1.0(0.5-2.0)$ & 100.0 & $2.0(1.0-2.0)$ & 100.0 & $0.5(0.5-2.0)$ & 100.0 \\
\hline & CIP & $4.0(0.25-8.0)$ & 11.1 & $4.0(2.0-4.0)$ & 0.0 & $4.0(2.0-4.0)$ & 0.0 \\
\hline & MIN & $0.5(0.5-1.0)$ & 100.0 & $0.12(0.06-0.12)$ & 100.0 & $1.0(0.5-1.0)$ & 100.0 \\
\hline & TMP-SMX & $0.12(0.12-0.25)$ & 100.0 & $0.12(0.12)$ & 100.0 & $0.12(0.12-0.25)$ & 100.0 \\
\hline \multirow[t]{4}{*}{ N. farcinica-935 } & AMK & $0.5(0.5-1.0)$ & 100.0 & $1.0(0.5-2.0)$ & 100.0 & $0.5(0.5-1.0)$ & 100.0 \\
\hline & CIP & $64.0(32.0-64.0)$ & 0.0 & $64.0(32.0-64.0)$ & 0.0 & $16.0(16.0-32.0)$ & 0.0 \\
\hline & MIN & $0.12(0.06-1.0)$ & 100.0 & $0.06(0.06-2.0)$ & 91.6 & $0.06(0.06-0.12)$ & 100.0 \\
\hline & TMP-SMX & $1.0(0.25-4.0)$ & 83.3 & $4.0(0.25-8.0)$ & 41.6 & $0.25(0.25-1.0)$ & 100.0 \\
\hline \multirow[t]{4}{*}{ N. otitidiscaviarum-779 } & AMK & $0.5(0.5-1.0)$ & 100.0 & $0.5(0.5-1.0)$ & 100.0 & $0.5(0.5-1.0)$ & 100.0 \\
\hline & CIP & $4.0(4.0-64.0)$ & 0.0 & $8.0(8.0-16.0)$ & 0.0 & $8.0(1.0-4.0)$ & 33.3 \\
\hline & MIN & $0.06(0.06-0.25)$ & 100.0 & $0.06(0.06-1.0)$ & 100.0 & $0.06(0.06-0.25)$ & 100.0 \\
\hline & TMP-SMX & $0.5(0.25-0.5)$ & 100.0 & $0.5(0.25-8.0)$ & 62.5 & $0.5(0.12-1.0)$ & 100.0 \\
\hline \multirow[t]{4}{*}{ N. asteroides-788 } & AMK & $0.5(0.5-1.0)$ & 100.0 & $1.0(0.5-2.0)$ & 100.0 & $0.5(0.5)$ & 100.0 \\
\hline & CIP & $0.5(0.25-2.0)$ & 100.0 & $0.5(0.5-2.0)$ & 100.0 & $0.25(0.25-1.0)$ & 100.0 \\
\hline & MIN & $4.0(2.0-4.0)$ & 0.0 & $4.0(4.0-8.0)$ & 0.0 & $2.0(2.0-4.0)$ & 0.0 \\
\hline & TMP-SMX & $2.0(0.25-4.0)$ & 75.0 & $2.0(0.25-32.0)$ & 50 & $0.25(0.12-0.5)$ & 100.0 \\
\hline
\end{tabular}


Table.1 (continued)

\begin{tabular}{|c|c|c|c|c|c|c|c|}
\hline \multirow[t]{3}{*}{ Isolates } & \multirow[t]{3}{*}{ Drugs } & \multicolumn{4}{|l|}{ Visual Readings } & \multirow{2}{*}{\multicolumn{2}{|c|}{ OD Readings }} \\
\hline & & \multicolumn{2}{|l|}{ Gold Standard } & \multicolumn{2}{|l|}{ With Resazurin } & & \\
\hline & & Modal MIC (range) & ${ }^{\mathrm{a} S u s c . ~(\%)}$ & Modal MIC (range) & ${ }^{\mathrm{a}}$ Susc. (\%) & Modal MIC (range) & ${ }^{\mathrm{a} S u s c .}(\%)$ \\
\hline \multirow[t]{4}{*}{ N. otitidiscaviarum-937 } & AMK & $0.5(0.5-1.0)$ & 100.0 & $0.5-1.0(1.0)$ & 100.0 & $0.5(0.5-1.0)$ & 100.0 \\
\hline & CIP & $2.0(1.0-2.0)$ & 22.2 & $2.0(2.0-4.0)$ & 0.0 & $2.0(0.25-2.0)$ & 28.6 \\
\hline & MIN & $0.06(0.06-0.12)$ & 100.0 & $0.06(0.06-1.0)$ & 100.0 & $0.06(0.06-0.25)$ & 100.0 \\
\hline & TMP-SMX & $1.0(0.25-1.0)$ & 100.0 & $1.0(0.25-2.0)$ & 100.0 & $0.25(0.12-0.5)$ & 100.0 \\
\hline \multirow[t]{4}{*}{ N. beijingensis-1180 } & AMK & $0.5(0.5-1.0)$ & 100.0 & $0.5(0.5-1.0)$ & 100.0 & $0.5(0.5)$ & 100.0 \\
\hline & CIP & $2.0(2.0-4.0)$ & 0.0 & $4.0(2.0-4.0)$ & 0.0 & $2.0(2.0-8.0)$ & 0.0 \\
\hline & MIN & $1.0(0.5-2.0)$ & 60.0 & $1.0(1.0-2.0)$ & 90.0 & $2.0(1.0-4.0)$ & 30.0 \\
\hline & TMP-SMX & $0.12(0.12-0.25)$ & 100.0 & $0.12(0.12-0.25)$ & 100.0 & $0.12(0.12-1.0)$ & 100.0 \\
\hline \multirow[t]{4}{*}{ N. beijingensis-1181 } & AMK & $0.5(0.5-1.0)$ & 100.0 & $0.5(0.5-1.0)$ & 100.0 & $0.5(0.5-1.0)$ & 100.0 \\
\hline & CIP & $4.0(1.0-4.0)$ & 9.1 & $4.0(0.12-8.0)$ & 20.0 & $4.0(2.0-4.0)$ & 0.0 \\
\hline & MIN & $1.0(0.5-2.0)$ & 60.0 & $1.0(0.5-2.0)$ & 66.6 & $2.0(1.0-4.0)$ & 20.0 \\
\hline & TMP-SMX & $0.12(0.12-0.25)$ & 100.0 & $0.12(0.12-0.25)$ & 100.0 & $0.12(0.12-0.5)$ & 100.0 \\
\hline \multirow[t]{4}{*}{ N. farcinica-2901 } & AMK & $1.0(1.0-2.0)$ & 100.0 & $2.0(2.0-4.0)$ & 100.0 & $1.0(1.0)$ & 100.0 \\
\hline & CIP & $0.25(0.25)$ & 100.0 & $0.5(0.25-4.0)$ & 85.7 & $0.25(0.25)$ & 100.0 \\
\hline & MIN & $2.0(2.0)$ & 0.0 & $2.0(2.0)$ & 0.0 & $2.0(1.0-2.0)$ & 50.0 \\
\hline & TMP-SMX & $8.0(4.0-8.0)$ & 0.0 & $16.0(16.0)$ & 0.0 & $1.0(0.5-1.0)$ & 100.0 \\
\hline
\end{tabular}

${ }^{a}$ Percentage of Susceptibility

The Disk Diffusion test is recommended by the CLSI [7] to confirm MIC results from Nocardia spp. isolates with breakpoints at the limit between antimicrobial susceptibility and resistance, for there is no classification of intermediate resistance for TMP-SMX. Fortyfour assays were performed with Nocardia spp. isolates and all were susceptible to this drug. In addition, the inter-reading comparison between the Gold Standard and the Disk Diffusion tests showed $97.7 \%$ of Categorical Agreement, and 2.27\% of Very Major errors (Table 3).

For TMP-SMX, the Essential Agreements, the Pearson's r-values with 95\% CI, the Categorical Agreements and Errors were calculated for the intra- and inter-reading methods comparisons considering \pm 1 and \pm 2 two-fold dilutions for concordant results. The percentages of EA on both intra- and inter-reading comparisons increased when \pm 2 two-fold dilutions were considered, nevertheless, the Pearson's r-values were significant on all comparisons $(P<0.0001)$. The inter-reading comparison between the Gold Standard and the OD readings showed $91.7 \%$ of CA with \pm 1 two-fold and $93.9 \%$ with \pm 2 two-fold dilutions. Despite of CA being greater than $90 \%$, the percentage of Very Major errors for \pm 1 two-fold and \pm 2 two-fold dilutions were 8.33 and $6.06 \%$, respectively (Table 3 ).

\section{Discussion}

The broth microdilution test determines the MIC of an antimicrobial agent, however, the interpretation of results is still challenging for isolates of Nocardia spp. The results are visually determined, and therefore, subjective and more prone to errors by laboratory technicians [15].

If there is doubt about the MIC results of TMP-SMX by the broth microdilution method, CLSI recommends the Disk Diffusion test to be performed [7]. In fact, we found difficult to determine the susceptibility classification of the $N$. brasiliensis-514 isolate by the broth microdilution method, with MICs varying between susceptible and resistant ranges. Hence, the Disk Diffusion test was employed and it was easy to read and to determine this isolate as susceptible for TMP-SMX.

The Resazurin readings in this study determined the MIC after $72 \mathrm{~h}$ of incubation, and resulted on the resistance to CIP of $N$. otitidiscaviarum and $N$. beijingensis, as well as the susceptibility to AMK and TMP-SMX of all isolates. These data are similar to that previously reported on Nocardia spp. isolates and the use of Alamar Blue [16], which is a commercial dye solution of Resazurin [17]. We also showed high percentages of Categorical Agreement between the Gold Standard and the Resazurin readings (71.7-100\%), corroborating with the statement from Zhao et al. that the test is cheap and reliable and its application in Nocardia sp. could improve 
Table 2 Agreements (\%) on comparisons within and between reading methods for BMD of Nocardia spp. isolates

\begin{tabular}{|c|c|c|c|c|c|}
\hline Drugs & Agreement & & Gold Standard & Resazurin & OD \\
\hline \multirow[t]{8}{*}{ AMK } & Essential & Intra-reading & 98.4 & 97.6 & 98.3 \\
\hline & & alnter-reading & - & 90.8 & 99.2 \\
\hline & & a,bearson's r (95\% Cl) & - & $0.50(0.36-0.63)$ & $0.92(0.88-0.94)$ \\
\hline & Categorical & Intra-reading & 100.0 & 100.0 & 100.0 \\
\hline & & alnter-reading & - & 100.0 & 100.0 \\
\hline & & aErrors: Very Major & - & 0.0 & 0.0 \\
\hline & & Major & - & 0.0 & 0.0 \\
\hline & & Minor & - & $c_{\text {n.a. }}$ & $c_{\text {n.a. }}$ \\
\hline \multirow[t]{8}{*}{ CIP } & Essential & Intra-reading & 91.7 & 94.4 & 93.4 \\
\hline & & anter-reading & - & 90.7 & 89.4 \\
\hline & & a,bearson's r $(95 \%$ Cl) & - & $0.69(0.58-0.77)$ & $0.82(0.76-0.87)$ \\
\hline & Categorical & Intra-reading & 82.7 & 88.1 & 77.9 \\
\hline & & anter-reading & - & 73.7 & 75.0 \\
\hline & & aErrors: Very Major & - & 0.85 & 3.79 \\
\hline & & Major & - & 4.24 & 1.52 \\
\hline & & Minor & - & 21.2 & 19.7 \\
\hline \multirow[t]{8}{*}{ MIN } & Essential & Intra-reading & 87.2 & 78.8 & 91.5 \\
\hline & & alnter-reading & - & 80.0 & 93.8 \\
\hline & & a,bearson's r $(95 \%$ Cl) & - & $0.90(0.86-0.92)$ & $0.90(0.87-0.93)$ \\
\hline & Categorical & Intra & 88.0 & 89.8 & 91.5 \\
\hline & & alnter & - & 85.6 & 87.7 \\
\hline & & aErrors: Very Major & - & 0.0 & 0.0 \\
\hline & & Major & - & 0.0 & 0.0 \\
\hline & & Minor & - & 14.4 & 12.3 \\
\hline
\end{tabular}

${ }^{a}$ Compared with the Gold Standard

${ }^{\mathrm{b}} P<0.0001$ for all comparisons

'Not applicable

Table.3 Agreements within and between susceptibility assays of Nocardia spp. isolates with TMP-SMX

\begin{tabular}{|c|c|c|c|c|c|c|c|}
\hline \multirow[t]{3}{*}{ Agreement } & \multicolumn{6}{|c|}{${ }^{\mathrm{a} B r o t h}$ Microdilution Method } & \multirow[t]{3}{*}{ Disk Diffusion } \\
\hline & \multicolumn{2}{|c|}{ Gold Standard } & \multicolumn{2}{|l|}{ Resazurin } & \multicolumn{2}{|l|}{ OD } & \\
\hline & \pm 1 & \pm 2 & \pm 1 & \pm 2 & \pm 1 & \pm 2 & \\
\hline \multicolumn{8}{|l|}{ Essential } \\
\hline Intra-reading & 82.0 & 97.0 & 73.1 & 88.5 & 81.8 & 93.9 & ${ }^{d}$ n.a. \\
\hline bInter-reading & - & - & 71.7 & 89.8 & 75.0 & 88.6 & ${ }^{d}$ n.a. \\
\hline b,c Pearson's $r$ & - & - & 0.50 & 0.42 & 0.36 & 0.44 & ${ }^{d}$ n.a. \\
\hline$(95 \% \mathrm{Cl})$ & & & $(0.36-0.62)$ & $(0.26-0.55)$ & $(0.20-0.45)$ & $(0.30-0.57)$ & \\
\hline \multicolumn{8}{|l|}{ Categorical } \\
\hline Intra-reading & 95.5 & 88.5 & 86.2 & 86.2 & 99.2 & 97.0 & 100.0 \\
\hline bInter-reading & $\longrightarrow$ & - & 81.1 & 91.3 & 91.7 & 93.9 & 97.7 \\
\hline bVery Major Errors & $\longrightarrow$ & - & 0.0 & 0.0 & 8.33 & 6.06 & 2.27 \\
\hline bMajor Errors & $\longrightarrow$ & $\longrightarrow$ & 18.9 & 8.66 & 0.0 & 0.0 & 0.0 \\
\hline
\end{tabular}

${ }^{\mathrm{a}} \mathrm{BMD}$ method concordant results considering \pm 1 or \pm 2 two-fold dilutions

${ }^{\mathrm{b}}$ Compared with the Gold Standard BMD method

${ }^{c} P<0.0001$ for all comparisons

${ }^{\mathrm{d}}$ Not applicable 
the international standardization of susceptibility testing methods [16].

The comparisons between the Gold Standard and the OD readings showed high percentages of Essential (75.0-99.2\%) and Categorical (75.0-100\%) Agreements. Similarly, Meletiadis et al. demonstrated that the European Committee on Antimicrobial Susceptibility Testing (EUCAST) spectrophotometric MIC determination for antifungal susceptibility testing with Aspergillus spp. isolates was in excellent Essential (92-97\%) and Categorical (93-99\%) Agreements with the visual MIC determination [14].

To the best of our knowledge, there are no studies using Spectrophotometry (OD readings) for Nocardia spp., but our results demonstrate its applicability for these bacteria, as it is currently used for fungal agents.

EUCAST, unlike CLSI, does not have a specific recommendation or defined breakpoints for Nocardia sp., however, their documents are free of charge and easily accessible to clinical laboratories for other microorganisms. CLSI documents, on the other hand, are only available through a costly payment, which can restrict their access and hinder their use by emerging countries. We showed that the use of Resazurin and Spectrophotometry could help defining a novel document and breakpoints for Nocardia spp. isolates.

The small number of Nocardia spp. isolates and evaluated drugs were the main limitations of this study. Nevertheless, the results herein disclosed the promising use of Resazurin and OD readings in future investigations on antimicrobial susceptibility of Nocardia spp. isolates.

\section{Conclusions}

Our data suggest that Resazurin and Spectrophotometry are efficient, reproducible and easy-to-use alternative methods for determining the susceptibility profile of Nocardia spp.

\section{Methods}

\section{Nocardia spp. isolates and ATCC strain}

Nocardia spp. isolates from the Collection of Cultures of the Laboratory of Medical Research in Mycology (LIM53) were included in this study $(n=15$; Table 1$)$. Eight isolates were identified in a previous study [4] and the other seven Nocardia beijingensis( $N$. beijingensis)-1180 (MW348983), N. beijingensis-1181 (MW348984), Nocardia brasiliensis(N. brasiliensis)-95 (MW348931), N. brasiliensis-129 (MW348933), N. brasiliensis-519 (MW348935), Nocardia farcinica( $N$. farcinica)-788 (MW348936), and N. farcinica-2901 (MW348955) were identified by Gram and Ziehl Neelsen staining methods, morphological characteristics and molecular sequencing. A $606 \mathrm{bp}$ fragment of the $16 S \mathrm{rRNA}$ gene was amplified with the primers Noc1 (5'-GCTTAACACATGCAAGTC G-3') and Noc2 (5'-GAATTCCAGTCTCCCCTG-3'), and sequenced as previously described [18]. The species was confirmed by comparing them against type strain sequences with the BLAST algorithm v.2.2.10 (http:// www.ncbi.nlm.nih.gov/BLAST). Similarity values of $\geq 98.0 \%$ for $16 S$ rRNA were deemed to indicate the same species.

CLSI-recommended quality control ranges for Amikacin (AMK), Ciprofloxacin (CIP), Minocycline (MIN) and Trimethoprim-Sulfamethoxazole (TMP-SMX) were performed by using a strain of Staphylococcus aureus ( $S$. aureus ATCC 29213) [7]. Nocardia spp. isolates were cultured on Tryptone Soy Agar (TSA; Kasvi, Italy) at $35^{\circ} \mathrm{C}$ for 7 days and the ATCC strain was also cultured on TSA at $35^{\circ} \mathrm{C}$ for $24 \mathrm{~h}$.

\section{Resazurin solution}

The $0.01 \%$ Resazurin solution was prepared by dissolving the powder dye (Sigma-Aldrich, Munich, Germany) in $1 \times$ PBS, pH 7.2 (Life Technologies, Carlsbad, CA, USA). After complete dissolution, the solution was sterilized by a $0.22 \mu \mathrm{m}$ membrane filtration, stored at $4{ }^{\circ} \mathrm{C}$, protected from light, and used within 3 days.

\section{Antimicrobial solutions}

The antimicrobial solutions were prepared as recommended by the CLSI document M100-S24 [19]. Briefly, each antimicrobial agent (all from Sigma-Aldrich, Munich, Germany) was dissolved and diluted separately: $A M K$ and MIN were dissolved and diluted in water; CIP was dissolved in Hydrochloric Acid $0.1 \mathrm{~N}$ and diluted in water; TMP was dissolved in Lactic Acid $0.05 \mathrm{M}$ and diluted in warm water; and SMX was dissolved in Sodium Hydroxide $2.5 \mathrm{M}$ and diluted in water. The drugs were two-fold serially diluted in CAMHB in 96-well microplates $(100 \mu \mathrm{L} /$ well; flat-bottomed cell culture microplates from Corning, Durham, NC, USA) at the following concentration ranges: $0.5-256.0 \mathrm{mg} / \mathrm{L}$ for AMK, $0.12-64.0 \mathrm{mg} / \mathrm{L}$ for CIP, $0.06-32.0 \mathrm{mg} / \mathrm{L}$ for MIN, and $0.12-64.0 / 2.37-1216.0 \mathrm{mg} / \mathrm{L}$ for TMP-SMX. The microplates were frozen at $-80^{\circ} \mathrm{C}$ until use.

\section{Antimicrobial susceptibility test}

The MICs were determined by the BMD method, according to CLSI document M24 for Nocardia [7]. Briefly, inoculum suspensions for each Nocardia isolate were prepared by dissolving the bacterial content with saline and glass microbeads (Sigma Aldrich, Munich, Germany), vortexing vigorously and then allowing it to precipitate for 10 to $15 \mathrm{~min}$. The concentration was adjusted by dilution on Cation-Adjusted Mueller-Hinton Broth 
(CAMHB; Becton Dickinson and Company, Sparks, MD, USA).

Medium control wells had $200 \mu \mathrm{L} /$ well of drug-free $\mathrm{CAMHB}$, and inoculum control wells had $100 \mu \mathrm{L} /$ well of drug-free CAMHB and $100 \mu \mathrm{L} /$ well of bacterial inoculum. All the other wells were inoculated with $100 \mu \mathrm{L} /$ well of bacterial inoculum on microplates with antimicrobial solutions, previously prepared. Microplates were incubated in a moist chamber at $35^{\circ} \mathrm{C}$.

Following incubation of $24 \mathrm{~h}, 20 \mu \mathrm{L} /$ well of $0.01 \%$ sterile resazurin solution were added to all wells and microplates were re-incubated for $48 \mathrm{~h}$ for colour development. A change in colour from blue to pink indicated bacterial growth.

The ATCC strain inoculum suspension was prepared as described for Nocardia isolates, except for the incubation period. After incubation for $17 \mathrm{~h}, 20 \mu \mathrm{L} /$ well of $0.01 \%$ sterile resazurin solution were added to all wells and the microplates were re-incubated for more $3 \mathrm{~h}$ for colour development.

Following the stablished incubation periods for the ATCC strain (17 and 20h) and for Nocardia isolates (48 and $72 \mathrm{~h}$ ), the microplates were evaluated by the Gold Standard visual reading without any dye, the visual reading with Resazurin, or by OD readings without any dye, at $560 \mathrm{~nm}$ in the Versa Max Microplate Reader spectrophotometer (Molecular Devices, Sunnyvale, CA, USA).

\section{Quality control}

Growth in medium control wells indicated contamination or absence of growth in inoculum control wells indicated unviability of the isolate, and the corresponding assay was discarded. At least two wells were matched among the triplicates for a valid result.

\section{Disk diffusion test}

The Disk Diffusion test was performed with the isolates suspensions, prepared as described on M24 CLSI document for Nocardia [7], and plated on 90-mm-diameter Mueller-Hinton agar plates (DME, Araçatuba, SP, Brazil). Antimicrobial disks of TMP-SMX $(25.0 \mu \mathrm{g}$; Sensidisc, DME, Araçatuba, SP, Brazil) were then placed on the agar, and the plates were incubated at $35^{\circ} \mathrm{C}$ for 3 to 5 days. Interpretive categories of Disk Diffusion results for Nocardia spp. isolates were based on the M24 CLSI document: a zone of $\geq 35 \mathrm{~mm}$ indicated susceptibility, and a zone of $\leq 15 \mathrm{~mm}$ indicated resistance.

\section{Analysis}

For the visual interpretation of the results, the MIC well was determined by its comparison with medium and inoculum drug-free control wells. The MIC well was the one with the lowest drug concentration that prevented the bacterial growth and the colour change within the incubation period, being similar to the medium control well (no visible growth and blue with Resazurin). The inoculum with drug and the inoculum control drug-free wells should show visible growth and should be pink with resorufin. For the spectrophotometric readings, the percentages of bacterial growth were calculated with the following eq. [20]: bacterial growth percentage $(\%)=(O D$ from the inoculum with drug well - the OD from the medium control well) / (OD from the inoculum control drug-free well - OD the OD from the medium control well $) \times 100$. The MIC well was the one with the lowest drug concentration with $\leq 10 \%$ of bacterial growth [14].

The Pearson Correlation Coefficients (Pearson's $r$ ) and respective $95 \%$ Confidence Intervals $(95 \% \mathrm{CI})$ were determined by the Prism 5.01 statistical software (GraphPad, San Diego, CA, USA).

\section{Abbreviations}

BMD: Broth Microdilution; AMK: Amikacin; CIP: Ciprofloxacin; MIN: Minocycline; TMP-SMX:Trimethoprim-Sulfamethoxazole; MIC: Minimum Inhibitory Concentration; OD: Optical Densities; CA: Categorical Agreement; EA: Essential Agreement

\section{Acknowledgements}

We thank Silvia Figueiredo Costa and Roberta Cristina Ruedas Martins (Laboratory of Bacteriology, HCFMUSP), and Erica Chimara da Silva (Adolfo Lutz Institute, Sao Paulo, SP, Brazil) for providing some of the antimicrobial agents and for the technical assistance.

\section{Authors' contributions}

Conceptualization: VC, MG, PS; Methodology:VC, MG, PS; Formal analysis: VC, PS; Investigation: VC, SN, PS; Writing - original draft preparation: VC, PS; Writing - review and editing: VC, MG, GB, ML, PS; Supervision: GB, ML. All authors have read and agreed to the published version of the manuscript, and agreed both to be personally accountable for the author's own contributions and to ensure that questions related to the accuracy or integrity of any part of the work, even ones in which the author was not personally involved, are appropriately investigated, resolved, and the resolution documented in the literature.

Funding

Not applicable.

\section{Availability of data and materials}

The datasets used and/or analysed during the current study are available from the corresponding author on reasonable request.

\section{Declarations}

\section{Ethics approval and consent to participate}

Approval (036/19) was obtained from the ethics committee of Faculdade de Medicina FMUSP, Universidade de Sao Paulo, Sao Paulo, Brazil.

\section{Consent for publication}

Not applicable.

\section{Competing interests}

The authors declare no competing interests.

\section{Author details}

${ }^{1}$ Laboratory of Medical Investigation in Immunology (LIM48), Hospital das Clinicas HCFMUSP, Faculdade de Medicina, Universidade de Sao Paulo, Av. Dr. Eneas Carvalho de Aguiar 470, IMT 2, terreo, Sao Paulo, SP 05403-000, Brazil. 
${ }^{2}$ Department of Infectious Diseases, FMUSP, Universidade de Sao Paulo, Sao Paulo, Brazil. ${ }^{3}$ Programa de Aprimoramento Profissional, HCFMUSP (LIM48), Sao Paulo, Brazil. ${ }^{4}$ Laboratory of Medical Investigation in Micology (LIM53), HCFMUSP, Sao Paulo, Brazil. ${ }^{5}$ Instituto de Medicina Tropical de Sao Paulo, Faculdade de Medicina FMUSP, Universidade de Sao Paulo, Sao Paulo, Brazil.

${ }^{6}$ Present Address: Faculdades Oswaldo Cruz, Sao Paulo, Brazil.

Received: 3 October 2021 Accepted: 19 November 2021

Published online: 05 December 2021

\section{References}

1. Wilson JW. Nocardiosis: updates and clinical overview. Mayo Clin Proc. 2012. https://doi.org/10.1016/j.mayocp.2011.11.016.

2. Beaman BL, Burnside J, Edwards B, Causey W. Nocardial infections in the United States, 1972-1974. J Infect Dis. 1976. https://doi.org/10.1093/ infdis/134.3.286

3. MCNeil MM, Brown JM. The medically important aerobic actinomycetes: epidemiology and microbiology. Clin Microbiol Rev. 1994. https://doi. org/10.1128/CMR.7.3.357.

4. Muricy EC, Lemes RA, Bombarda S, Ferrazoli L, Chimara E. Differentiation between Nocardia spp. and Mycobacterium spp.: critical aspects for bacteriological diagnosis. Rev Inst Med Trop Sao Paulo. 2014. https://doi. org/10.1590/s0036-46652014000500005.

5. Bibi S, Irfan S, Zafar A, Khan E. Isolation frequency and susceptibility patterns of Nocardia species at a tertiary hospital laboratory in Karachi, Pakistan. J Infect Dev Ctries. 2011. https://doi.org/10.3855/jidc.1278.

6. Condas LA, Ribeiro MG, Muro MD, de Vargas AP, Matsuzawa T, Yazawa $\mathrm{K}$, et al. Molecular identification and antimicrobial resistance pattern of seven clinical isolates of Nocardia spp. in Brazil. Rev Inst Med Trop Sao Paulo. 2015. https://doi.org/10.1590/S0036-46652015000300012.

7. Clinical and Laboratory Standards Institute. Susceptibility testing of mycobacteria, Nocardiae, and other aerobic actinomycetes. Approved standard, 3rd ed. CLSI Document M24. Wayne: Clinical and Laboratory Standards Institute; 2018.

8. Brown-Elliott BA, Brown JM, Conville PS, Wallace RJ Jr. Clinical and laboratory features of the Nocardia spp. based on current molecular taxonomy. Clin Microbiol Rev. 2006. https://doi.org/10.1128/CMR.19.2.259-282.2006.

9. Palomino JC, Martin A, Camacho M, Guerra H, Swings J, Portaels F. Resazurin microtiter assay plate: simple and inexpensive method for detection of drug resistance in Mycobacterium tuberculosis. Antimicrob Agents Chemother. 2002. https://doi.org/10.1128/aac.46.8.2720-2722.2002.

10. Castilho AL, Caleffi-Ferracioli KR, Canezin PH, Dias Siqueira VL, de Lima Scodro RB, Cardoso RF. Detection of drug susceptibility in rapidly growing mycobacteria by resazurin broth microdilution assay. J Microbiol Methods. 2015. https://doi.org/10.1016/j.mimet.2015.02.007.

11. de Paula e Silva AC, Oliveira HC, Silva JF, Sangalli-Leite F, Scorzoni L, FuscoAlmeida AM, et al. Microplate alamarBlue assay for Paracoccidioides susceptibility testing. J Clin Microbiol. 2013. https://doi.org/10.1128/JCM. 02914-12.

12. Al-Hatmi AM, Normand AC, Ranque S, Piarroux R, de Hoog GS, Meletiadis J, et al. Comparative evaluation of Etest, EUCAST, and CLSI methods for amphotericin B, voriconazole, and posaconazole against clinically relevant Fusarium species. Antimicrob Agents Chemother. 2016. https:// doi.org/10.1128/AAC.01671-16.

13. Foerster S, Desilvestro V, Hathaway LJ, Althaus CL, Unemo M. A new rapid resazurin-based microdilution assay for antimicrobial susceptibility testing of Neisseria gonorrhoeae. J Antimicrob Chemother. 2017. https://doi. org/10.1093/jac/dkx113.

14. Meletiadis J, Leth Mortensen K, Verweij PE, Mouton JW, Arendrup MC. Spectrophotometric reading of EUCAST antifungal susceptibility testing of Aspergillus fumigatus. Clin Microbiol Infect. 2017. https://doi.org/10. 1016/j.cmi.2016.10.017.

15. Conville PS, Brown-Elliott BA, Smith T, Zelazny AM. The complexities of Nocardia taxonomy and identification. J Clin Microbiol. 2018. https://doi. org/10.1128/JCM.01419-17.

16. Zhao P, Zhang X, Du P, Li G, Li L, Li Z. Susceptibility profiles of Nocardia spp. to antimicrobial and antituberculotic agents detected by a microplate Alamar Blue assay. Sci Rep. 2017. https://doi.org/10.1038/srep43660.
17. O'Brien J, Wilson I, Orton T, Pognan F. Investigation of the Alamar Blue (resazurin) fluorescent dye for the assessment of mammalian cell cytotoxicity. Eur J Biochem. 2000;267:5421-6. https://doi.org/10.1046/j.14321327.2000.01606.x.

18. Rodríguez-Nava V, Couble A, Devulder G, Flandrois JP, Boiron P, Laurent F. Use of PCR-restriction enzyme pattern analysis and sequencing database for hsp65 gene-based identification of Nocardia species. J Clin Microbiol. 2006. https://doi.org/10.1128/JCM.44.2.536-546.2006.

19. Clinical and Laboratory Standards Institute. Performance standards for antimicrobial susceptibility testing: informational supplement. CLSI document M100-S24. Wayne: Clinical and Laboratory Standards Institute; 2014

20. Liu M, Seidel V, Katerere DR, Gray Al. Colorimetric broth microdilution method for the antifungal screening of plant extracts against yeasts. Methods. 2007. https://doi.org/10.1016/j.ymeth.2007.02.013.

\section{Publisher's Note}

Springer Nature remains neutral with regard to jurisdictional claims in published maps and institutional affiliations.
Ready to submit your research? Choose BMC and benefit from:

- fast, convenient online submission

- thorough peer review by experienced researchers in your field

- rapid publication on acceptance

- support for research data, including large and complex data types

- gold Open Access which fosters wider collaboration and increased citations

- maximum visibility for your research: over $100 \mathrm{M}$ website views per year

At BMC, research is always in progress.

Learn more biomedcentral.com/submissions 